\title{
Communication Strategy in the Implementation of Expanding Maternal and Neonatal Survival Policy
}

\author{
S. K. Habsari, Sofiah, Sumardiyono \\ English Department, Communication Department, HIPERKES \\ Sebelas Maret University \\ Surakarta, INDONESIA \\ skhabsari_uns@yahoo.co.id
}

\begin{abstract}
The purpose of this article is to describe the communication strategy and to identify the obstacles faced by both the upper and lower level of the society in implementing EMAS. Research has been carried out in Brebes Regency because of the high case of maternal mortality. Data are compiled through various methods: observation, interview, FGD, and textual analysis and analyzed with interactive analysis model of Miles and Huberman. Finding shows that Brebes has built networking with lower levels of society to socialize the programs through various media and forums in order to educate, to motivate, to persuade the society the importance of maternal health. However, this research also identifies some obstacles in program implementation. Finding shows the relatively refusal of all level of society in the ICT and the persistence of both the upper level to mobilize the society perception to change the myth and the lower level to accept the modern perspective on maternal health issues. Drawing from the relatively persistence of the society and the richness of local culture, the research suggests that rather than confronting the myth, local perspective should be considered as a strength in program implementation.
\end{abstract}

Keywords- EMAS, MMR (Maternal Mortality Ratio), ICT (Information Communication Technology)

\section{INTRODUCTION}

Since 2003, the global rate of maternal mortality decline has accelerated to $5.5 \%$ average annually. However, it is still under the target of Millennium Development Goals 5 which has set a target of a 75 reduction in the ratio of mortality. [1] In Indonesia, the ratio of maternal mortality is relatively high. It is slightly reduced from 210 per 100.000 live birth in 2010 to 190 per 100.000 live birth in 2013 [2]. However, in 2014 the maternal mortality ratio increases to 220 and put Indonesia in the position of the highest in maternal mortality rate compared to the other countries in Southeast Asia such as Philippines (99); Malaysia (29); Brunei (24); Thailand (40); Sri Lanka (35); Thailand (48); Vietnam (59); and Burma (200). [3] The global commitment on maternal related issues, synergized through reducing maternal mortality and achieving universal access to reproductive health are addressed to reach the goals: (1) universal education, (2) reduction of infant and child mortality, and (3) reduction of maternal mortality and (4) access to reproductive and sexual health services including family planning. [4] Thus, it is a challenge of Indonesia to reduce the ratio of maternal mortality from 190 in 2013 to nearly 100 per 100.000 live birth in 2015 to meet one the MGD's goals.

Reports issued by UNFPA, UNICEF and BAPPENAS show there is a decreasing ratio of Maternal Mortality from 1994 to 2008. Reports also show that the ratio of Maternal Mortality has varied from one district to another district in every province in Indonesia.[5] However, data of 2014 shows that it is a slightly increase from 2013 to 2014 which means that it needs to seriously address to reach the target of $25 \%$ reduction by 2015 The Indonesian Demographic and Health Survey (SDKI) has indicated that the major causes of maternal death are hemorrhage (28\%), eclampsia (24\%), sepsis $(11 \%)$, abortion complication (6\%), obstructed labor (5\%), and others $(26 \%)$. The high ratio of maternal mortality is a reflection of complex issues which need to address. Although data show that 74.9 births are attended by skilled health providers, the disparities among provinces and regencies are relatively large. Level of poverty varies from one area to the other area. The impoverished is mostly the group who do not have access to Emergency Obstetric Care, safe and effective Family Planning methods, prevention and management of Reproductive Tract Infections, including Sexually Transmitted Diseases. Considering the disparities, the key strategy to reduce maternal mortality is by recruiting community midwives at the local level and ensure that every district, including the remotes area there is an adequate health services. Government has also provided additional incentives to doctors and midwives who are placed in remote areas. However, the standard and the quality of services are questionable. There is no adequate support such as equipment, medication, IEC (Information, Education and Communication), appropriate in-service training because of geographical barriers and high cost. [6]

Previous studies on maternal mortality have been conducted to identify the underlying problems of the reluctance of reducing Maternal Mortality Rates. Theoretical and empirical information on various causes of maternal mortality has been established to assist addressing the issues. However, maternal mortality remains high in many countries. It raises various questions of the effectivity of standard programs. Some researchers, for example, question safe-motherhood strategies, especially the implementation of the intervention. Criticism to 
component programs is also raised because they are developed "based on low-grade evidence derived from retrospective and observational studies, as well as on empirical knowledge and conclusions reached via deductive reasoning". [7] Similar finding has also been reported by the Centre for Health Policy. It has been found out that there are well-documented reports on strategies for promoting safe motherhood. However, the reach, accessibility and acceptability of interventions related to health systems, health promotion and the social determinants of health are rarely discussed. Most findings show that the focus of the researches is on addressing clinical interventions to reduce maternal mortality. [8] Various researches have also been conducted on cultural factors affecting the implementation of interventions across diverse settings in all world regions. Some findings reveal the examples of good practice and success stories although they do not provide sufficient details of the cultural factors. Others consider culture as a barrier to maternal health service use. Most researches are on addressing social and economic context. Unfortunately, it still focuses on sub-population of high income countries. [9] Different study is conducted in Indonesia, especially in Bali, focusing on wide range of Maternal Mortality Ratio estimation. Because maternal mortality rate is one of the indicators of measuring standards of public health, Department of Health, Republic of Indonesia, has applied various methods to obtain maternal mortality statistics, such as using sisterhood method and perspective (direct) community based service. However, the sisterhood method is more familiar to apply for measuring Maternal Mortality Ratio. This method is also useful for planners to design interventions and monitoring the impacts. [10] Situated on the previous researches addressing on maternal mortality issues, this article participates on discussion of cultural factors affecting the implementation of EMAS program in Indonesia. Rather than considering the cultural factors as an obstacle in reaching the goal, this research prefers to identify to local potency of the community to mobilize the people to program implementation. The implication expected is the changing perspective of the society on maternal health issues.

Various attempts have been conducted in response to follow the global commitment to address maternal health. Government of Indonesia has produced Law No. 23 / 1992 on Health, (2) Amendment of Law No 10 / 1992 on population and family development, and (3) Conduct a National Workshop on Reproductive Health in 1996 with the main output of the establishment of National Committee on Reproductive Health. Various workshops have been conducted also to direct policies and strategies for intervention, monitor task forces activities, and facilitate collaboration with other relevant parties. Government of Indonesia has also launched the Making Pregnancy Safer initiative and produced Law No. 22/199 and Law No. 25/1999 to ensure that all levels (central, provinces and regencies) address that issue and also produce various programs and approaches to improve maternal health. [11]

One of the strategies to achieve the progress of decreasing MMR is to finance maternal health through government intervention. Previous study conducted by Women Research Institute (WRI) shows that despite the mandate of the Health
Law No. 36/2009 which requires local government to allocate $10 \%$ of Regional Development Budget (APBD) for health expenditure, many public health services either community healthcare service (Puskesmas) or public regional hospital (RSUD) have raised the cost of health services to increase PAD Net Regional Income (PAD). The cost of health services has impacted women from the poor families to obtain sufficient treatments when needed. WRI also identifies that there are several reasons that influence women reluctance to visit health services, other than expense. Many women in rural areas consider midwives' services are not complete compared to those offered by traditional birth attendants. Services offered by traditional birth attendants are not only prenatal and during the delivery process, but also including care for the newborn infant and the entire family. Women in rural areas also believe to the spiritual power of traditional birth attendants. They are able to give comfort and assurance to mothers before, during and after the process of delivery. Besides, many women are not in powerful position to decide who is going to assist on their baby delivery. Many women must still comply with decision made by their husband and family. In conclusion, lack of access to adequate reproductive health facilities contributes to the relatively high Maternal Mortality Ratio in Indonesia. [12]

In 2011, USAID in cooperation with the government of Indonesia has launched EMAS (Expanding Maternal and Neonatal Survival) program in 2011 implemented in 6 provinces with the highest ratio of maternal and infant mortality: North Sumatra, Banten, West Java, Central Java, East Java and South Sulawesi. The USAID/Indonesia EMAS Project is a 5-year program to support the government of Indonesia to reduce maternal and newborn mortality. The expected result of the project is an overall $25 \%$ decline in national maternal and newborn mortality through working with all levels of government, civil society organization, public and private health facilities, health professional organizations and the private sectors. One of the strategies developed by EMAS project is to oversee the cross-cutting governance and information and communication technology activities in addressing both the supply and demand sides of the service delivery system. [13]

Central Java province is the second highest ratio of maternal mortality. Brebes is the highest among any other regencies in Central Java. Data show that there were 60 cases of maternal mortality in Brebes in 2013 and unfortunately it still increases to 73 cases in 2015 although EMAS program has been launched there since 2011. It raises a question of the implementation of the program, especially the barriers which hinder the progress of maternal mortality decline. Focusing on the communication system strategy of intervention developed by EMAS program, this article focuses on describing the communication strategy of intervention designed to implement the policy of EMAS in Brebes regency and identifying the obstacles faced by both the upper and lower level of the society in implementing the policy of EMAS in Brebes regency. It is also to find out the local potency of the society in developing strategy of development communication. 


\section{MATERNAL HEALTH, MATERNAL MORTALITY AND EMAS PROGRAM}

As reported, Women Research Institutes finds out that Maternal Mortality is still serious problem in Indonesia. WRI also identifies some challenges that the government of Indonesia needs to address to reduce Maternal Mortality Ratio: (1) Inaccessibility to quality health care facilities; (2) Lack of trained health care-givers; (3) Lack of knowledge and awareness of the society concerning maternal health issues; (4) Low health status and nutritional levels of pregnant women; (5) Low level usage of contraception and high levels of unmet needs; (6) Inaccurate measurement of MMR. [14]

The international forums have identified factors that influence maternal health. Overall, the reluctant progress to reduce Maternal Mortality Ratio is caused by data gaps, inconsistent indicators and frequent revision [15]. United Nations Population Fund finds out that substandard health services and lack of available medical equipment and supplies at the time of labor, delivery, and immediately baby birth are factors that cause maternal deaths. Health facility staffs are not professional, treating patients unsympathetically and uncaringly. This could lead women to use the services of traditional birth attendants. It is also identified that midwives do not have necessary skills, adequate to care during labor, birth, and postpartum and immediate newborn periods. A skillful birth attendant refers to the ability to manage normal deliveries, recognize the onset complications, perform essential interventions, start treatment, and refer obstetric emergencies when they are beyond their competence. Lack of skills can be correlated to lack of adequate supplies, equipment, and infrastructure as well as an efficient and effective system of communication and referral. There is also geographical barrier factor, disability and distance to healthcare services that lead to delay to get treatment. Vehicle shortage and poor road conditions hinders the women to get emergency treatment. [16]

UNICEF has identified the economic disparities in AsiaPacific region that underlies discrimination against women and girl which has resulted on the high Maternal Mortality Ratio. The strategy is to fill in the gap through providing expenditure on woman and children health and education. [17] Oxfam has adopted the MDGs to develop several approaches to tackle maternal mortality since the high level of maternal mortality reflects a violation of human rights. Since 1987, it has been developed an international target setting to reduce maternal mortality. Over the time, with increasing awareness of maternal health, the attitude toward maternal mortality has been changed. However, the result of the shift is not similar in every country. Oxfam identifies that there are some obstacles which need to address. One of the main obstacles is the failure to finance maternal health. Some developing countries should make a commitment to reduce Maternal Mortality Ratio and mobilize necessary resources to improve health services. Special attention should be focused on health care services that are responsive to women's needs. And in the implementation, monitoring and evaluation should be developed because engagement with powerful critique is significant for all working with reducing maternal mortality. [18]
There are various strategies that can be implemented to reduce maternal mortality ratio. WHO requires every country to develop high-functioning maternal health program with the awareness of a changing epidemiological landscape underlying the primary causes of maternal mortality. Strategies could be developed through initially understanding immediate and underlying causes and followed by designing intervention programs with context-specific and evidence-informed to prevent future mortality. [19]

Various approaches have been applied to reach the expected level of decline of the ratio of maternal mortality. As mentioned previously, government has been taking various intervention to address the problem, such as producing policies to cover various problems that hinder to improve maternal health. In some way, it shows the seriousness of the government to meet the goal of $25 \%$ reduction of maternal mortality rate. However, as it is mentioned previously it is often lack of central government financial support. Most program finance is under local government budget and unfortunately, the budget allocation of every region is not the same. Through EMAS project, Cooperative Agreement Number AID-497-A-11-00014, \$55 million program to support the government of Indonesia, various disparities existed in relation to both services and finance could be addressed.

EMAS program is implemented to improve the quality of emergency obstetric and neonatal care services and increase the efficiency and effectiveness of referral systems between hospitals and community healthcare center. EMAS is implemented by JHPIEGO, with international partners RTI (Research Triangle International), Save the Children and local partners Health Institution Budi Kemuliaan and Muhammadiyah. EMAS has applied Vanguard system through interfering the management system especially in relation to maternal health. Intervention is conducted to improve the quality of emergency services of healthcare facilities, PONED (Basic Essential Neonatal Obstetric Services) and PONEK (emergency Neonatal Obstetric Services), to ensure the intervention of medical priority result in big effect of the decline of mortality applied both in hospitals and community healthcare services. In improving the effectiveness and efficiency of the referral systems between community healthcare services and hospitals and the role of society in guaranteeing the accountability and the quality of health services and local government and also to improve the access of the society in using the health services, EMAS applies various strategies of intervention to reach the goals. All programs have been designed to result national effect. It also utilizes the latest information technology. SMS, hotline, and media social are used to improve the effectiveness and efficiency of emergency services, effective referral from the primary healthcare facility, efficient and safe treatment for the maternal and neonatal health care. [16]

\section{METHOD OF RESEARCH}

The location of research is Brebes regency. The research design is descriptive qualitative. Primary data are collected through direct observation, Focus Group Discussion and interview to any related individuals, such as women who are visiting the community healthcare services, public figures, 
governmental staffs, society midwives, doctors and healthcare service staffs. Secondary data are taken from any related documents. Data validity is internal data validity with triangulation system application, through comparing, doing check and recheck the quality of information or data from various information. It is applied to find out the convergence of data compilation from various sources and informants. Data analysis technique is worked through model interactive system of Miles and Huberman. [17]

\section{FINDING AND DISCUSSION}

\section{A. EMAS Strategy of Intervention and Society Perception on EMAS}

Maternal and newborn mortality is a complex problem that needs cooperation of various parties to reach the target of $25 \%$ national decline by 2016. Government of Indonesia has a commitment to decline the ratio because good maternal health is an economic investment and can increase to productivity. The government has created an environment to enhance problem recognition of maternal health issues through providing information, developing and implementing national policies, intervention to change the social norms, providing access to quality information and services and improving financial coverage for the poor.

Strategy of intervention has been developed by local government of Brebes in addressing the implementation of EMAS program which shows the seriousness of Brebes in meeting the target of maternal mortality rate decline. The local government has produce some regulations such as the Regent Circular Letter no. 300.1/01/761/XIII/2013 on acceleration effort of maternal and neonatal mortality decline; the Regent Circular Letter on the four hand baby delivery; the Regent regulation no. 47/2012 on expanding breastfeeding; the Regent Certificate on forming crisis team center of KIA (maternal and baby health); the Regent Regulation of Information for traditional birth attendant. These regulations are socialized through letters and direct information in a monthly meeting to all related parties, such as local government, districts, community healthcare services, village heads. [18] However, finding shows that only governmental staffs are aware with the regulation. Meanwhile, most people, the lower level of society feels unfamiliar with the regulation.

To execute the regulation showing the seriousness to reach the goal, Brebes continually socializes the program through banners, brochures and posters which can be found on community healthcare services. However, the local government does not cooperate with communication institution such private or public radio or print media or internet to communicate the program. People are aware with EMAS when they read the banners or the poster which illustrate various information on maternal health but it is still considered "just a government program". With the distance feeling to the program, it could mean two things: the reluctance of the society to accept the program as they do not need it or the unawareness of the society of the importance of maternal health in their life.

The target of EMAS is women in their fertility age. The main goal is to change the perspective of the society that maternal health is worth investment in their life. EMAS has designed various strategies which address the gaps found out from previous researches on MMR. EMAS has identified the disparities of health services among several areas because of geographical barriers. Access to standard health services are limited in some remote areas. Lack of adequate health services are addressed through improving the quality of emergency obstetric and neonatal care services and increase the efficiency. People are aware with maternal health but it is often too late when there is obstructed labor. Intervention to clinical management system is applied to community healthcare services through capacity building of the society midwives. The society midwives are invited to attend a refresher course in certain community healthcare services to extend their skill and knowledge to manage obstructed labors. A simulation kits and manuals are developed to enable them to manage complications in pregnancy and childbirth.

The fast development of communication technology, especially the popularity of mobile phone for all levels of society in some way can be used as a tool to communicate the program from the local government to the community. It also can be used as a medium from the society to express their questions and criticism. EMAS has developed the technique of SMS Bunda by registering day of birth to 08118469469 to get any information on maternal health from education on pregnancy to antenatal care. However, as the community still feels unfamiliar with the program, none of the community in Brebes regency use this medium to express their concern. In line with previous research on technology, gender and development, it can be interpreted that although most women have used mobile phone for communication, the deployment of its technology is still limited. In their perspective, mobile phone is only a medium for communication between people.

EMAS has also identified that many cases of maternal mortality are caused by the lateness of getting adequate treatment when it is considered as medical emergency. EMAS has designed SIJARI EMAS (Networking System of EMAS), an integrated system to optimize the information delivery process and communication of emergency referral system and referral readiness of community healthcare services and hospitals on maternal and neonatal care. So, it improves the linkages and strengthens the networks of hospitals and community healthcare services. Using mobile and web-based technology, the referral time between hospitals and community healthcare services is shortened. [19]

A belief that pregnancy is natural for women is still strong in the community. They are not aware that for some women their pregnancy can be considered as high risk that need special treatment from earlier stage of their pregnancy. Women could develop complication during pregnancy or after giving birth leading to the highest lifetime risk. Getting appropriate health facility in timely manner and life-saving treatment can be challenging in remote areas. Labor and delivery complication lead to the death is caused by delay factors: delay in detecting the high risk and taking decision, delay to give referral, delay to get treatment. But, it could be caused also by too young, too old and too many. Those are considered factors of high risk. The "delay" and "too" factors can be minimized through strengthening the referral system. Putting in place a set of 
standards and regular audits to both the hospitals and community healthcare services could minimize the late treatment of emergency cases.

However, finding shows that hospitals are often too late in response to emergency cases referred by community healthcare services. Community healthcare services as the primary services has been prepared with the referral system but some referral hospitals are not well-equipped with standards, either staffs or tools to accept the referral that could reduce the delays. Delays in response increase the emergency level twice more and it leads to life threatening. Some referral hospitals do not respond to the hotline call from the community healthcare services that leads to the untreated emergency treatment. Some delay factors are nonstandard equipment and outdated website, limited human resources, and overload work. It is often that the sound of SIJARIEMAS is considered disturbing for some staffs as it is too loud. Because they reduce the sound, hotline calls are often unattended.

EMAS also develops SIGAPKU (systems and processes for receiving and responding to feedback) about the quality care, such as SMS-based Citizen Gateway. EMAS believes the role of civil to ensure high levels of accountability. By applying two community-based mechanism, EMAS goes through community-based groups, civic forums, and a group of health motivators to communicate the services that are available for women and their families and to encourage citizens' participation for monitoring the quality of services. With feedback mechanism of SIGAPKU, it is expected to encourage society's involvement to promote transparence and strengthen accountability. Barriers of healthcare services and government accountability for delivering high quality services can be caused by few expectations and lack of knowledge about acceptable standards of care of service users. Through SMS to SIGAPKU, EMAS facilitates the process of defining and socializing service charters. [20]

Unfortunately, finding shows that there is no mechanism of SIGAPKU applied in Brebes. Communication about EMAS to all levels of society does not work as expected. Not all society are aware the availability of maternal health services and they do not have a medium to complain the inadequate provision of the healthcare services. Thus, there are still emergency cases untreated adequately.

\section{B. Districts Communication Strategy for Program Implementation}

Communication strategy developed in district level, especially developed community healthcare service has a purpose to execute the regulation produced by the local government of Brebes in an attempt to reduce the ratio of maternal and newborn mortality. As it is required by EMAS to use two community-based mechanisms, the local government of Brebes lets every districts to develop its own program to socialize EMAS to its community. As the target of the program is the community, they have to know EMAS programs and the purpose of the programs. However, the geographical condition of Brebes laying from coastal to mountainous areas with complexities of population, to educate the society and to socialize the program are big homework for the regency.
Brebes consists of 17 districts administratively with 292 villages and 4 sub-districts. Every district has one or two community healthcare services which act as the program implementation unit. Every community healthcare services in every district are responsible for designing and executing maternal health communication strategies and the degree to which communication efforts are integrated into other health program initiatives. Thus, every community health care service has distinctive way to educate the community to increase knowledge and change attitudes to maternal health.

Most districts use banners to create an awareness of the society on maternal health. They send messages of the need to take care their pregnancy. With texts "kehamilan adalah anugrah" (pregnancy is a gift), "kelahiran bayi adalah amanah" (baby is responsibility), "ikut mengawasi ibu hamil sampai lahir" (actively support pregnancy and delivery) and "menuju ibu sehat dan bayi selamat" (have healthy mother and safe delivery), the community health service campaigns the behavioral change of that pregnancy is natural and participatory of society that pregnancy and safe delivery needs support from family and society.

Brochures are also used to educate the society. This medium could expand the society's knowledge on safe pregnancy through detail information written on the brochures. Various topics, such as Program Perencanaan Persalinan dan (Program for birth plan and avoidance of complication), Bayi Berat Lahir Rendah (Low birth weight), Perawatan Bayi Baru Lahir (infant and newborn care), Kesehatan Reproduksi (reproduction health), Air Susu Ibu Eksklusif (Exclusive breastfeeding), Perilaku Hidup Bersih dan Sehat Healthy clean lifestyle), Merawat Kehamilan (pregnancy care), etc. have been simplified for ease of read.

Posters are also informative. Posters mounted to the walls, such as integrated antenatal service flow, high risk pregnancy, breastfeeding tips, referral requirements guide, etc. are intended to influence behavior change. Reading posters make society firstly aware of the service and knowledgeable about desired behaviors. Then, it is expected that they approve and intend to take the message personally. Practicing and advocating others then will lead to the behavioral change as expected by the program.

Previous researches on maternal mortality show that cultural aspects can hinder the success of reducing MMR. In response to fill the gap, EMAS suggests the districts to socialize the programs through community-based groups and civic forums. District health motivators need cooperate with local leaders. The most difficult task of health motivators is to change the perspective of the society that their labor and delivery should be attended by skillful birth attendants. Although trainings to enhance the skill of community midwives have been facilitated in order to produce a trust from the society of the professionalism of the health service staffs, it does not make people change their perception. Although they are aware of the program, they prefer traditional birth attendant to help the delivery. Most women acknowledge the professional skill of midwives in assisting delivery. However, they are still reluctant to go to midwives. Traditional birth attendants are considered suitable with their needs because they 
do not only assist the delivery but also look after both the mother and the baby after the delivery. Beliefs in the society that after delivery women need special care (massage and some herbal drinks) only provided by traditional birth attendants are still strong in the society. When question of the possibility of high risk pregnancy which could lead to maternal death is raised, they consider the tragedy just as destiny. To force the society to go to midwives to get checks on their pregnancy in order to identify the possibility of high risk pregnancy treated earlier, districts have produced a penalty for this practice of going to traditional birth attendants for delivery assistance. They fine the traditional birth attendants who perform this practice. However, it does not work. The practice continues because they are protected by the society. They do not inform that they have been attended by traditional birth attendants, rather they inform the delivery as "kebrojolan" (earlier than expected date delivery). Although the district recognizes the practice, the staffs are also reluctant to fine the traditional birth attendants. To respond to this problem, some districts develop special training for traditional birth attendances. The community health service provides a facility of a meeting forum (arisan) for traditional birth attendance. In every meeting, a staff from community health service give some talks on how to identify high risk pregnancy and on improving their skill of assisting delivery to meet health standard. The practice does not work on every district. It shows that every district develops its own creativity to address the problem.

Integration into other health program initiatives is a strategic communication design. Different area means different audiences. Thus, it needs different messages and sometimes different approaches, whether through interpersonal channels or community channels. In some districts, health motivators cooperate with some community groups to socialize the program. They work with group of pregnancy class, community women organization, group of traditional birth attendance and group of community midwives. Health motivators build interpersonal communication with the head of the groups. Information on the program is communicated interpersonally because the head of the group will be the speaker in socializing the program. It is important that the speaker is from the group because the speaker needs to establish influences. As it is integrated with community groups, it is continually responsive to changing environment and practical for different setting application. The speakers just insert the message within any other activity and on other situation they can advocate in interpersonal way. Because the speakers are from the group, they speak similar language and share similar codes. Thus, barriers of communication can be hindered. Through this strategy, it is expected that there will be behavioral change of the society on maternal health.

\section{CONCLUSION}

In EMAS program implementation, Brebes regency has developed various communication strategies to reach the goal. Brebes has identified that the success of the program depends on three aspects: the intervention to healthcare services management system, the awareness of the society and strategic design of communication. The underlying problem of the low decline of maternal mortality is on society's perception that "pregnancy and delivery are natural for women". Besides, there is a gap between healthcare providers and society especially on maternal health issues. The main homework is how to enhance society's knowledge on maternal health issues through creating a process of behavioral change which lead to the success of the program.

The first strategy is to develop programs of intervention on management system, especially referral system. To change society's perception that labor and delivery need to be attended by a skillful health worker, a series of refresher course is facilitated to enhance the skills of society midwives in attending labor and delivery process. However, this strategy does not work as expected. Although the skill of the community midwives improves and they are able to mane manage normal labor and delivery and able to diagnose, manage and refer to hospital for obstetric emergencies, delay cases are still unavoidable. Nonstandard equipment and outdated website, limited human resources, and overload work are factors of delay which lead to maternal death.

The substantive growth in new information and communication technologies, such as mobile phone has provided new opportunities of behavioral change of maternal health. Brebes regency facilitated by EMAS program has applied communication strategy of SIJARI EMAS and SIGAPKU to improve linkages among community health care services and hospitals and educate the society of standards of services. However, many of them are not aware with the existence of this medium and the importance of this medium. It shows that instead of the fast development of communication technology and the popularity of mobile phone, some societies prefer to continue their tradition, such holding regular meetings and gathering.

Local government of Brebes is aware of the potency of the community. The complexity of the geography laying from coastal to mountainous area makes every area have its own specificity. Strategic communication developed by Brebes is to coordinate with every community healthcare services in every district and give them freedom to use its potencies. Rather than making a conflict with traditional birth attendants, some districts facilitate regular meetings of a group of traditional birth attendants. They are considered as potency that could be enhanced rather than barrier of success. In this meeting, health motivator as representative of district community healthcare service could insert some knowledge on how to detect high risk pregnancy. Some work with a group of women communities which are another potency of the regency. The tradition of gathering could be used as medium of communicating the program. However, rather than attending and socializing personally, the health motivators prefer to create interpersonal communication with the head of the groups and hand on the socialization on their behalf. As the head of the community groups shares similar language and codes with the members, the socialization can work successfully without any refusal from the community. From this strategy, it is expected that the goal of the program can be reached. Moreover, it can change the perspective of the society on the importance of maternal health in their life. With this strategy, it can lead to the empowerment of the society. 


\section{REFERENCES}

[1] Guttmacher Institute, "Maternal mortality is declining but not enough to meet Millennium Development Goal 5" in International Perspective on Sexual and Reproductive Health, vol. 40, no. 2, 2014

[2] Maternal Mortality Ratio (Modeled, Estimate, per 100,000 live births), http://data.worldbank.org/indicator/SH.STA.MMRT), 2015 [Oct 9, 2015]

[3] Maternal Mortality Rate, http://www.indexmundi.com/g/r.aspx?v=2223, 2014 [Oct 8, 2015]

[4] Sarah Zureick-Brown, Holly Nemby, Doris Chou, Nobuko Mizoguchi, Lale Say, Emi Suzuki, and John Wilmoth, "Understanding global trends in Maternal Mortality" in Int Perspect Sex Reprod Health, Vol. 39, No. $1,2013$.

[5] Maternal Mortality Ratio, http://indonesia.unfpa.org/issues-andchallenges/maternal-mortality-ratio) [Oct 8, 2015]

[6] Adriana Noerdin, In Search of a Spearhead to Reduce Maternal Mortality in Indonesia. Jakarta: Women Research Institute, 2011, pp. 1-2

[7] Diana Gil-Gonzales, Mercedes Carrasco-Portino, Maria Teresa Ruiz, "Knowledge gaps in scientific literature on maternal mortality: a systematoc review" in Bulletin of the World Health Organization, Vol. 84, No. 11, 2006, pp. 903-909.

[8] Matthew Chersich, Mapping maternal health research in low-middle income (LMIC) countries, March 2014 www.chp.ac.za/.../Policy\%20Brief\%20Mascot\%20systematic\%20revie w... [Oct 8, 2015]

[9] Ernestina Coast, Eleri Jones, Anayda Portela, Samantha R. Lattof, Meternity Care Services and Culture; A Systematic Global Mapping Interventions. 2014 http://journals.plos.org/ploseone/article?id=10.3/journal.pone. 0108130 [Oct 8, 2015]

[10] Dewa Nyoman Wirawan and Michael Linnan. "The Bali Indirect Maternal Mortality Study" in Source: Studies in Family Planning, Vol. 25, No. 5,1994, pp. 304-309

[11] Access and utilization of health facilities and services for poor women, http://wri.or.id/en/home-en/177-current-project-en/womenhealth/maternal-mortality-rate/603-access-and-utilization-of-healthfacilities-and-services-for-poor-women\#.VoHedmBunIU

[12] Adriana Noerdin, In Search of a Spearhead to Reduce Materna Mortality in Indonesia. Jakarta: Women Research Institute, 2011, p. 3
[13] Elly Burhaini Faizal, "Maternal, infant deaths in 20 provinces remain high" in the Jakarta Post, May 2012 [Oct 8, 2015]

[14] Women Research Institute, Reducing the maternal mortality ratio (editorial), http://wri.or.id/en/editorial/210-reducing-the-maternalmortality-ratio\#.VoIAk2BunIU, 2015 [Oct 8, 2015]

[15] Sima Sajedinejad, Reza Majdzadeh, AbouAli Vedadhir, Mahmoud Ghazi Tabatabaei, Kazem Mohammad, "Maternal mortality: a crosssectional study in global health" in Globalization and Health, Vol. 11, No. 4, 2015 .

[16] Tej Ram Jat, P. R. Deo, I. Goicolea, A-K. Hurtig, M.S. Sebastian "Socio-cultural and service delivery dimensions of maternal mortality in rural central India: a qualitative exploration using human rights lens" $[\mathrm{J}]$ Global Health Action, vol. 8, 2015.

[17] "Maternal mortality" in Reproductive Health Matters, Vol. 16, No. 32, 2008, p. 208.

[18] Arabella Fraser, "Approaches to reducing maternal mortality: Oxfam and MDGs" in Gender and Development, Vo. 13, No. 1, 2005, pp. 36 43.

[19] World Health Organization. Strategies toward Ending Preventable Maternal Mortality (EPMM). Geneva: WHO Press, 2015

[20] Expanding Maternal and Newborn Suvival, http://www.healthynewbornnetwork.org/partner/expanding-maternaland-newborn-survival-emas [Oct 9, 2015]

[21] Mathew B. Miles and M. Huberman. Qualitative Data analysis. London: SAGE Publications, 1994

[22] World Health Organization, Skill attendant at birth http://www.who.int/gho/maternal health/skilled care/skilled birth atten dance text/en/http://www.rti.org/page.cfm?obj=F669A6E2-0C76-638C8083263E9F8A55E9, 2015 [Oct 8, 2015]

[23] Women Research Institute, Access and utilization of health facilities and services for poor women, http://wri.or.id/en/home-en/177-currentproject-en/women-health/maternal-mortality-rate/603-access-andutilization-of-health-facilities-and-services-for-poorwomen\#.VoHedmBunIU, 2015 [Oct 8, 2015]

[24] EMAS, Referral system strengthening, http://emasindonesia.org/read/what_we_do/referral_system_strengthenin g, 2015 [Oct 8, 2015]

[25] EMAS, strengthening accountability, http://emasindonesia.org/read/what we do/strengthening accountability ,2015 [Oct 8, 2015] 